九州大学学術情報リポジトリ

Kyushu University Institutional Repository

\title{
Reactions and Behavior Relevant to Chemical and Physical Properties of Various Veterinary Antibiotics in Soil
}

Jeon, Dae S.

Department of Bio-Environmental Chemistry, College of Agriculture and Life science, Chungnam National University

Oh, Taek-Keun

Department of Bio-Environmental Chemistry, College ofAgriculture and Life science, Chungnam National University | Division of Soil and Fertilizer, NAAS

Park, Misuk

Department of Bio-Environmental Chemistry, College of Agriculture and Life science, Chungnam National University

Lee, Dong S.

Department of Bio-Environmental Chemistry, College of Agriculture and Life science, Chungnam National University

他

https://doi.org/10.5109/1467651

出版情報：九州大学大学院農学研究院紀要. 59 (2)，pp.391-397，2014-08-29. Faculty of Agriculture, Kyushu University

バージョン：

権利関係 : 


\title{
Reactions and Behavior Relevant to Chemical and Physical Properties of Various Veterinary Antibiotics in Soil
}

\author{
Dae S. JEON ${ }^{1}$, Taek-Keun OH ${ }^{1,2}$, Misuk PARK ${ }^{1}$, Dong S. LEE ${ }^{1}$, You J. LIM ${ }^{1}$, Ji S. SHIN ${ }^{1}$, \\ Seung G. SONG ${ }^{1}$, Sung C. KIM ${ }^{1}$, Yoshiyuki SHINOGI and Doug Y. CHUNG ${ }^{1 * *}$
}

\author{
Science for Bioproduction Environment, Faculty of Agriculture, Kyushu University, \\ Hakozaki 6-10-1, Higashi-ku, Fukuoka city 812-8581, Japan
}

(Received April 25, 2014 and accepted May 12, 2014)

\begin{abstract}
Due to possible environmental risks by a potential for reaching the surface and groundwater environment through soil for veterinary antibiotics (VAs) to treat disease and protect the health of animals, understanding reactivity and behavior of VAs have been recognized as one of the emerging issues in soil environment. VAs released via urine and faeces into the soil environment can be dispersed through a number of physical and chemical processes within soil. These processes including sorption, leaching and degradation being the three important processes in the soil-water systems are driven by the physico-chemical properties of the antibiotics, such as their molecular structure, size, shape, solubility, speciation, and hydrophobicity. However, only a few systematic investigations related to the reactions and behavior of VAs in soil exist. Therefore, the basic chemistry of these compounds should be understood before discussing their fate and transport of VAs in the soil environment. In this review, we have attempted to summarize the latest information available in the literature on the reactions and behavior of VAs in the soil environment.
\end{abstract}

Key words: Animal manure, Reactions and Behavior, Veterinary antibiotics, Soil

\section{INTRODUCTION}

The term "antibiotic" used to be restricted to antibacterials originally described only those formulations derived from living organisms but is now also applied to synthetic antimicrobials, such as the sulphonamides. Almost half of antibiotics produced in the world are used in farm animals, either as growth promoters or as therapeutic agents resistance (Sarmah et al., 2006; FDA, 2013). A recent survey from the Korean Ministry of Agriculture, Food, and Rural Affairs reported that the amount of antibiotics used for animal agriculture under highly intensive domestic husbandry conditions in Korea has been gradually decreased from 1594 tons in 2001 to 936 tons in 2012, with approximately 41\% reduction (MAFRA, 2013).

Veterinary antibiotics (VAs) and other medically important antimicrobial medications are often used in feed or water given to cattle, poultry, hogs and other animals to make animals grow faster and to compensate for overcrowded and unsanitary conditions. However, the world's public-health experts, from the European Union, the United States and the World Health Organization are agreed that the over-use and mis-use of VAs in intensive animal production is the major cause of the current crisis of antibiotic resistance (NIH, 1999).

Consumers in many advanced countries are no longer keen to eat livestock products including meat from the animals raised on feeds containing VAs because efforts are being made to ban their use due to legislation

${ }^{1}$ Department of Bio-Environmental Chemistry, College of Agriculture and Life science, Chungnam National University, Daejeon, 305-764, Korea

${ }^{2}$ Division of Soil and Fertilizer, NAAS, RDA, Suwon, 441-707, Korea

* Corresponding author (E-mail: dychung@cnu.ac.kr) to control use of antibiotics at least their non-therapeutic use (Pathak, 2010). The Food and Drug Administration (FDA) in USA has been known to implement a plan to phase out antibiotics and other medically important antimicrobial medications in animal foods over fears for antibiotic resistance because the over-use of antibiotics in human medicine is the major cause of the current crisis of antibiotic resistance (Sarmah et al., 2006; FDA, 2013). The Korean government also announced a total ban on inclusion of non-therapeutic VAs in feed for livestock intended to enhance the safety of domestic product in June 2012 (MAFRA, 2013) since the KMFA began to ban the use of nine antibiotics as feed additives in July 2010 (Renee, 2011).

Antibiotics can enter the environment by two ways, (i) directly when using the drugs i.e. the unabsorbed as waste and (ii) subsequent excretion of absorbed antibiotic residues and their metabolites through urine and feces of the animal. However, little information on reactions that can determine the fate and behavior of VAs with two types of substances such as hydrophilic or hydrophobic in the manure and slurry during storage period is available (Pathak, 2010). Due to a growing concern about the potential impact of antibiotic residues in soil due to increased land application of animal waste containing antibiotics to supplement fertilizer our focus is to add new information to existing literature data regarding to reactions and behavior relevant to chemical and physical properties of various VAs in the soil environment.

\section{Classification of VAs}

Of the drugs approved for animal health and management, more than $70 \%$ of all consumed pharmaceuticals are antibiotic agents (Kanfer et al., 1998; HallingSorensen et al., 1998). The antibiotics defined as a 
multitude of heterogeneous chemical compounds are synthesized through the secondary metabolism of living organisms, with exceptions for semi- or completely synthetic substances (Thiele-Bruhn, 2003). These antibiotics can be classified basically as "narrow-spectrum" or "broad-spectrum" depending on the range of bacterial types that they affect (Table 1). The term broad-spectrum antibiotic refers to an antibiotic that acts against a wide range of disease-causing bacteria, in contrast to a narrow-spectrum antibiotic, which is effective against specific families of bacteria (Clayton, 1993).

Classification of antibiotic substances produced naturally or synthetically is based on their usage at different fields (e.g. antimycotics for fungi, anti-infective acting against infection, anthelmintics for parasitic

Table 1. Antibiotics depending on the action of bacterial types

\begin{tabular}{ll}
\hline Spectrum & Antibiotics \\
\hline \multirow{2}{*}{ Broad } & $\begin{array}{l}\text { Amoxicillin, Levofloxacin, Gatifloxacillin, Streptomycin, Tetracycline, } \\
\text { Chloramphenicol, Ciprofloxacin,Cephalosporins, Macrolides, } \\
\text { Quinolones }\end{array}$ \\
\hline \multirow{2}{*}{ Narrow } & Azithromycin, Clarithromycin, Clindamycin, Erythromycin, \\
& Vancomycin, Penicillin, Aztreonam, Linezolid, Bacitracin, Teicoplanin, \\
& Viomycin, Isoniazid, Streptomycin, Streptogramins, Fidaxomicin
\end{tabular}

Table 2. Classes of antibiotic substances approved for use in food-producing animals

\begin{tabular}{ll}
\hline Classes & Antibiotics \\
\hline Aminocoumarins & Novobiocin \\
Aminoglycosides & Dihydrostreptomycin, Gentamicin,Neomycin,Spectinomycin, Streptomycin \\
Amphenicols & Florfenicol \\
Cephalosporins & CeftiofurCephapirin \\
Diaminopyrimidines & Ormetoprim \\
Fluoroquinolones & Danofloxacin,Enrofloxacin \\
Glycolipids & Bambermycins \\
Ionophores & Laidlomycin,Lasalocid,Monensin,Narasin,Salinomycin \\
Lincosamides & Lincomycin,Pirlimycin \\
Macrolides & Erythromycin,Gamithromycin,Tilmicosin,Tulathromycin,Tylosin \\
Penicillins & Amoxicillin,Ampicillin,Cloxacillin, Penicillin \\
Pleuromutilins & Tiamulin \\
Polypeptides & Bacitracin \\
Quinoxalines & Carbadox \\
Streptogramins & Virginiamycin \\
Sulfas & Sulfadimethoxine,Sulfamerazine,Sulfamethazine,Sulfaquinoxaline \\
Tetracyclines & Chlortetracycline,Oxytetracycline, Tetracycline \\
\hline
\end{tabular}

Table 3. Commonly used VAs for therapeutic and subtherapeutic purposes depending types of animal

\begin{tabular}{ll}
\hline Types & Antibiotics \\
\hline \multirow{2}{*}{ Swine } & $\begin{array}{l}\text { Apramycin, Arsanilic acid, Bacitracin zinc, Bambermycin, Carbaox, } \\
\text { Tylosin,Chlortetracycline, Lincomycin, Oxytetracycline, Penicillin, Roxarsone, } \\
\text { Tiamulin hydrogen fumerate, Tilmicosin, Virginiamycin }\end{array}$ \\
\hline $\begin{array}{l}\text { Beef and } \\
\text { Cow }\end{array}$ & $\begin{array}{l}\text { Bacitracin zinc, Bambermycin, Chlortetracycline, Laidlomycin,Lasalocid, } \\
\text { Monensin, Oxytetracycline, Tylosin, Virginiamycin, }\end{array}$ \\
& Apramycin, Arsanilic acid, \\
& Oxytetracycline,Chlortetracycline,Bambermycin,Bacitracin, Lincomycin, \\
& Penicillin, Roxarsone \\
Avoparcin, Spiramycin, Tylicin, Virginiamycin, Virginiamycin (Banned in EU)
\end{tabular}


worms in the body), in different structural classes (e.g. nucleosides, tetracyclines) and exhibit different molecular structures and diverse chemical and physical properties (Grafe, 1992). Amino glycosides, macrolides sulfonamides, $p$-Lactams, and tetracyclines are the classes of antibiotic compound with distinctive chemical properties depending on molecular structures (Thiele-Bruhn, 2003). Table 2 shows the main groups of important antibiotics categorized on the basis of chemical structure.

A partial list of antibiotics used in the production of swine, beef and cow, and poultry is listed in Table 3 (Regassa et al., 2009). And the most common antibiotics present in swine, beef, and poultry manures are tetracyclines (oxytetracycline and chlortetracycline), tylosin, sulfamethazine, amprolium, monensin, virginiamycin, penicillin, and nicarbazine. These antibiotics generally remain stable during manure storage and end up in agricultural fields on manure applications (Pathak, 2010).

\section{Physical and chemical characteristics of VAs}

The antibiotics which vary greatly in chemical structure and consist of a non-polar core and polar functional groups show a large number of chemical compounds, ranging from simple substances containing only carbon, hydrogen, and oxygen, to more complex forms which contain nitrogen, sulfur, and even chlorine (JuhelGaugain et al., 2000; Thiele-Bruhn, 2003).

Nucleosides and tetracycline are the VAs classified by different structural classes. Nucleosides that include cytidine, uridine, adenosine, guanosine, thymidine and inosine are glycosylamines consisting of a nucleobase bound to a ribose or deoxyribose sugar via a beta-glycosidic linkage (Fig. 1). It is well known that nucleosides may undergo partial or complete nucleoside bond hydrolysis to yield their corresponding sugars and nucleoside bases because nucleosides are susceptible to hydrolysis and followed by degradation processes such as deamination.

Tetracycline (TC) that belongs to a broad-spectrum polyketide antibiotic having anoctahydrotetracene-2carboxamide skeleton of polycyclic naphthacene ring (Fig. 2) shows a planar structure of four fused rings with hydrophilic groups on one face, hydrophobic groups on the other face and each ring including phenol, alcohol, ketone and amino. TC is unstable in acidic and alkaline media and relatively stable under neutral $\mathrm{pH}$ conditions ( $\mathrm{pH} 7)$.

Numerous antibiotics have low water solubility, and they are relatively polar, and strongly retarded in soils. But the solubility of most of the macrolide group of antibiotics is high and has been found to increase with an increase in solvent polarity (Wilson, 1981; Salvatore and Katz, 1993). Antibiotics belonged to the class of an amino glycosides which are molecules or portion of molecule composed of amino-modified sugars are basic, strongly polar polycationic compounds. They are water soluble, mostly hydrophilic, and susceptible to photo degradation (Thiele-Bruhn, 2003). Thus, the antibiot-<smiles>Nc1ncnc2[nH]cnc12</smilesNitrogenous base
(Nucleobase)
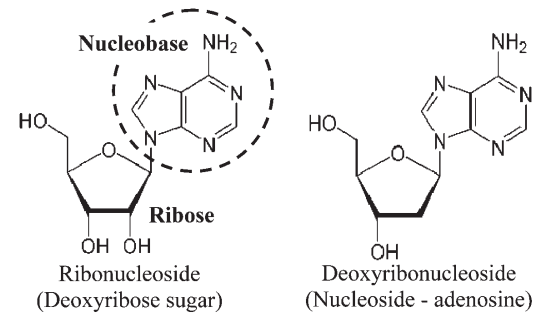

Fig. 1. The nucleoside adenosine, a component of RNA, results from the sugar ribose and adenine via the formation of an N-glycosidic bond.

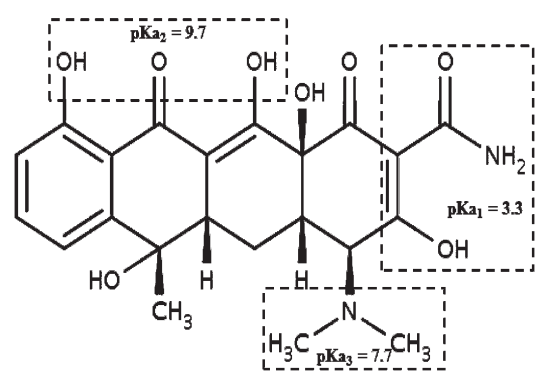

Fig. 2. Structure of tetracycline and $p K_{a}$ values.

ics can generally be strongly polar polycationic and the amphoteric carrying many $p K_{a}$ values as weak acids and form salts in strongly acidic or basic solutions. Most antibiotics can also be dissociated or protonated depending on the $\mathrm{pH}$ how acidic a solution is and $p K_{a}$ values indicating how acidic (or not) a given hydrogen atom in a molecule is associated with the different functional groups of the compounds (Thiele-Bruhn, 2003). For example, TCs, characterized by a partially conjugated four-ring structure with a carboxyamide functional group, are amphoteric compounds as characterized by four $p K_{a}$ values of approximately 3.3, 7.7, 9.7 and 10.7 depending on solution status between acid and base as shown in Fig. 2 (Thiele-Bruhn, 2003).

The antibiotics such as TCs are relatively stable in acids, but not in bases, and are capable of forming water-soluble salts with strong acids such as hydrochloric acid and strong bases such as sodium hydroxide and potassium hydroxide (Halling-Sorensen et al., 2002). And divalent and polyvalent metal ions can form insoluble salts with TCs, and so do salicilates, phosphates, citrates, polyvinylpyrrolidine, thiourea, lipoproteins, serum albumin, globulin and RNA. These salts of metal ions are insoluble in water at neutral conditions. Also TC exposed to dilute acid conditions undergoes dehydration to yield anhydrotetracycline which suffers further cleavage and lactonization to apoterramycin. All penicillins that are acid labile degrade in neutral or basic solutions. Table 4 represents the typical ranges of physicochemical properties from selected classes of antibiotics (Osol, 1980; Gruber et al., 1990; Asuquo and Piddock, 1993; Nowara et al., 1997; NIH, 1999; Rabolle and Spliid, 2000; SRC, 2001). 
Table 4. Typical ranges of physicochemical properties from selected classes of VAs

\begin{tabular}{|c|c|c|c|c|}
\hline VA Class & $\begin{array}{l}\text { Watersolubility } \\
\qquad\left(\mathrm{mg} \mathrm{l}^{-1}\right)\end{array}$ & $\log \mathrm{K}_{\mathrm{ow}}$ & $\mathrm{pK}_{\mathrm{a}}$ & Remarks \\
\hline Aminoglycosides & $\begin{array}{c}10 \\
\tilde{500}\end{array}$ & $\begin{array}{c}-8.1 \\
\sim \\
-0.8\end{array}$ & $\begin{array}{c}6.9 \\
\sim \\
8.5\end{array}$ & Neomycin, Streptomycin \\
\hline Macrolides & $\begin{array}{c}0.45 \\
\sim \\
15\end{array}$ & $\begin{array}{c}1.6 \\
\sim \\
3.1\end{array}$ & $\begin{array}{c}7.7 \\
\sim \\
8.9\end{array}$ & $\begin{array}{l}\text { Erythromycin, } \\
\text { Oleandomycin, Tylosin }\end{array}$ \\
\hline p-Lactams & $\begin{array}{c}22 \\
\sim \\
10100\end{array}$ & $\begin{array}{c}0.9 \\
\sim \\
2.9\end{array}$ & 2.7 & $\begin{array}{l}\text { Penicillins: Ampicillin, Meropenem, } \\
\text { Penicillin G; Cephalosporins: } \\
\text { Ceftiofur, }\end{array}$ \\
\hline Sulfonamides & $\begin{array}{c}7.5 \\
\sim \\
1500\end{array}$ & $\begin{array}{c}-0.1 \\
\sim \\
1.7\end{array}$ & $\begin{array}{c}2 \\
3 \sim 4.5 \\
10.6\end{array}$ & $\begin{array}{l}\text { Sulfanilamide, Sulfadiazine, } \\
\text { Sulfapyridine, Sulfadimidine, } \\
\text { Sulfadimethoxine, Sulfamethoxazole }\end{array}$ \\
\hline Tetracyclines & $\begin{array}{c}230 \\
\sim \\
52000\end{array}$ & $\begin{array}{c}-1.3 \\
\sim \\
0.05\end{array}$ & $\begin{array}{l}3.3 / 7.7 / 9.3 \\
2-3 / 4.5\end{array}$ & $\begin{array}{l}\text { Chlortetracycline, } \\
\text { Oxytetracycline, Tetracycline }\end{array}$ \\
\hline
\end{tabular}

For understanding the degree of hydrolysis of antibiotics, degradation pathways for some antibiotics are important, especially esters and amides which are common hydrolysis reaction sites on antibiotics (Waterman et al., 2002). The degree of antibiotic hydrolysis is highly dependent on $\mathrm{pH}$, temperature, and the presence of hydrolytically susceptible functional groups in the antibiotic structures (Mitchell et al., 2014). Hydrolysis rates are also affected by ionic strength (Mabey and Mill, 1978) as well as the presence of divalent metal ions (Gensmantel et al., 1980), oxide surfaces (Torrents and Stone 1994), and clays (Pusino et al., 1996). Generally, base-catalyzed hydrolysis predominates over acid-catalyzed and neutral $\mathrm{pH}$ hydrolysis for many organic compounds (Mabey and Mill, 1978; Mitchell et al., 2014), although water and hydroxide anion are both attracted to electron deficient atoms, hydroxide anion is a stronger nucleophile than water. Alternatively, hydrolysis may be catalyzed in acidic solutions when protons shift the electron density of a molecule, so that a susceptible site can be attacked by water (Larson and Weber, 1994).

\section{Reactions and behavior of VAs in Soil}

The use of animal manure as fertilizer and soil amendment can be a point source of antibiotic pollution to the environment. A great portion of antibiotic compounds fed to the animals as growth promoters or food additives may partially be metabolized in the organism and are excreted as the parent compound or as metabolites in urine and faeces before being discharged into agricultural soils directly through grazing livestock and indirectly through the animal manure and compost applied to the field (Halling-Soensen et al., 2002). Antibiotic compounds in animal's excrete can not only undergo transformations depending on the $\mathrm{pH}$ of the surroundings, but also retention of them are strongly influenced by soil/water distribution $\left(K_{d}\right)$ coefficients of antibiotics in soils. Thus, antibiotics enter the environment by two ways, (i) directly when using the antibiotic i.e. the unabsorbed as waste and (ii) subsequent excretion from antibiotic-laden manure residues and their metabolites through urine and feces of the animal (Pathak, 2010). The translocation and bioactivity of antibiotics are influenced by soil sorption, governing the distribution and transfer between phases and thus the resulting mobile and bioavailable fractions of the antibiotics. Possible entry paths of VAs are displayed in Fig. 3 (Nicole, 2008).

Once in the soil environment, distribution of antibiotics which are only slightly transformed, or even unchanged and conjugated to polar molecules can be dependent on the molecular structure of the compounds and its reactivity with other relevant factors such as physical-chemical properties of soil. Chemical

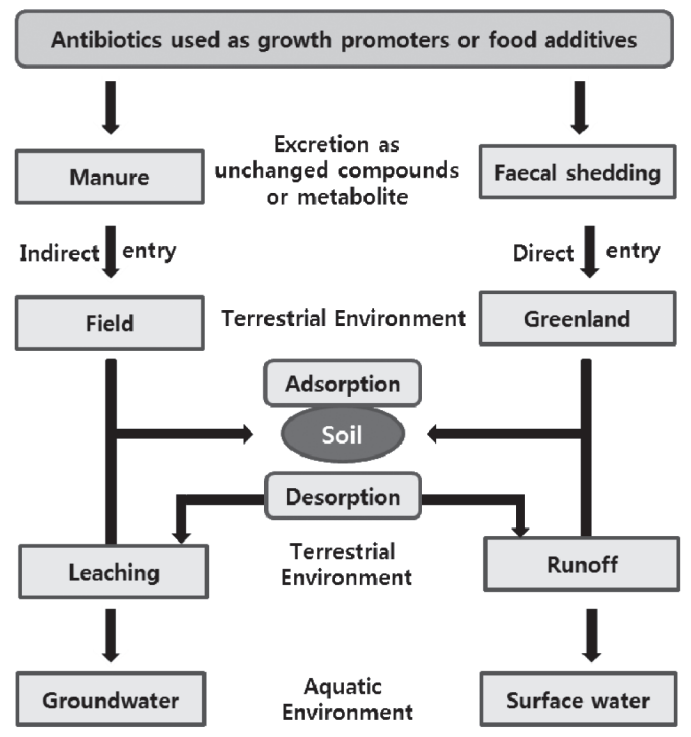

Fig. 3. Sources and possible entry paths of veterinary antibiotics in the environment. 
and physical behavior of antibiotic also depends on the physical-chemical properties of soil types, climatic conditions, and other various environmental factors (Nicole Kemper, 2008). The sorbed compounds pose a reservoir of pollutants that can be mobilized in soils and further contaminate ground water by leaching or by erosion to surface waters (Pedersen et al., 2003). However, important information on the reaction and behavior of antibiotics in soils is lacking (Sarmah et al., 2006).

And antibiotics can be divided into 4 groups depending on the reaction with the clay minerals (Table 5). Strongly basic and amphoteric groups of antibiotics react with the dominant clay minerals to form complexes. Strongly basic antibiotics can be so strongly held on the clay surface of montmorillonite, vermiculite or illite minerals, that they are virtually unreleasable as assessed from bioassay studies. In kaolinite, however, where it is not held that strongly, there is some release in case of streptomycin and dihydrostreptomycin (Pinck et al., $1961 \mathrm{a}, \mathrm{b}$ ).

Photolysis, hydrolysis, biodegradation and binding of the antibiotics on to soil particles are some of the reactions that can take place and determine their behavior in soil (Nicole Kemper, 2008). The antibiotics classified by different structural classes can be ionized, amphiphilic or amphoteric. Ionized antibiotics in soil can furnish positive charges that can be attracted on colloidal soil surface. The sorption and fixation of the VAs in soils differ considerably due to physical-chemical properties such as their molecular structure, size, shape, solubility and hydrophobicity (Thiele-Bruhn, 2003)

Thiele-Bruhn et al. (2004) also reported that sulfonamide sorption was influenced by: (i) the molecular structure and physicochemical properties of sulfonamides depending $\mathrm{pH}$, (ii) accessible functional groups at organic-mineral surfaces, and (iii) the accessibility of voids and cavities in the three-dimensional structure of soil organic matter and its combinations with the mineral matrix forming organic-mineral complexes.

Polar and lowly water soluble antibiotics that can be retained on the mineral and organic colloids in soil are less liable to degradation forces and less potent towards its targets. But antibiotics become more mobile when they may form complexes with soluble organic materials, resulting in contamination of groundwater while still in its parent form (Singh and Mishra, 2013; ThieleBruhn, 2003).

Table 5. Antibiotics depending on the reaction with the clay minerals

\begin{tabular}{ll}
\hline Category & Antibiotics \\
\hline \multirow{2}{*}{ Strongly basic } & $\begin{array}{l}\text { Streptomycin,Dihydrostreptomycin,Neomycin, } \\
\text { Kanamycin. }\end{array}$ \\
Amphoteric & Bacitracin, Aureomycin, Tetramycin \\
Acidic & Penicillin \\
Neutral & Chloromycetin, Cyclohexamide \\
\hline
\end{tabular}

The distribution coefficient $\left(K_{d}\right)$, the ratio of antibiotic concentration adsorbed in soil to the same in water in equilibrium with soil, determines the mobility of the antibiotics in soils. According to Sarmah et al. (2006), none of the soil properties showed positive correlation with the estimated $K_{d}$ for the antibiotics except few antibiotics such as tylosin although there was good positive correlation between the measured $K_{d}$ and OC, CEC and clay content of soils. Wide variation in tenacity of their adsorption on soil exchange sites is apparent from a wide range of observed distribution coefficient $\left(K_{d}\right)$ from 0.2 to as high as 6000 . Antibiotics with higher $K_{d}$ value are highly immobile due to strongly affinity to the soil particles. Therefore, transport and mobility the VAs within soil can be restricted to fast preferential and macropore flow for high $K_{d}$ and cotransport with mobile colloids facilitated by dissolve organic matter.

Adsorption of most antibiotics used as growth regulators to soils is fast and is high in clay and low in sand fractions. VAs react in varying degrees to form complexes with various clay minerals (Pinck et al., 1961 a, b). The adsorption of VAs to various exchange sites is characterized by two different processes of kinetics (Sithole and Guy, 1987; Suan and Dmitrenko, 1994) such as a fast initial adsorption to outer surfaces and rate-limited adsorption by a penetration into interlayers of clay minerals and micropores. The adsorption capacity for basic antibiotic such as tylosin is mainly due to the expanding characteristics of these clays with the consequent restriction of cation exchange to the outer surfaces of the clay particles (Bewick, 1979), that adsorption capacity are low for non-expanding lattice such as illite and kaolinite and high for expanding lattice such as bentonite and montmorillonite (Hillel, 1980). Strong adsorption through the ion exchange process may occur only if solution $\mathrm{pH}$ is less than the $p K_{a}$ value of the compound, while the surface acidity of clays can cause sorption by cation exchange well above the $p K_{a}$ (Figueroa et al., 2004; Sassman and Lee, 2005).

Strongly basic antibiotics that are so strongly held on the surface of clays can be transported mainly to surface waters with the sediments during run off losses of soil. Sorption coefficient $\left(K_{s}\right)$ of the VAs suggests how mobile the VAs would be in the soil environment. For example, the transport of tetracyclines seems to be restricted to fast preferential and macro-pore flow or to be facilitated by cotransport with mobile colloids such as dissolved organic matter (Thiele-Bruhn, 2003). And in case of amphoteric antibiotics, there is easy release from all kinds of clay minerals. The weakly adsorbed antibiotics can be more mobile and leach with percolating water. In general, affinity of many of the commonly used antibiotics is quite high to soil particles, indicating that most of the mobility of these antibiotics in terrestrial environment is probably due to runoff losses of antibiotic-laden sediments to surface waters from fields where antibiotic laden manures are applied. 


\section{DISCUSSION}

Many studies have shown that VAs administered to food-producing animals occur in stored liquid and solid manure of confined animal-feeding operations, are applied to fields through the application of manure, resulting in a growing international concern about the potential impact of antibiotic residues on the environment. The adsorbed VAs onto the soil particle surface or organic matter in soil can be mobilized and further contaminate ground water by leaching or by erosion to surface waters. However, important information on the reactivity and behavior of VAs given physical and chemical properties of soils within the soil environment is lacking. Therefore, there is an urgent need to gather precise information on the reactivity and relevant behavior of VAs in soil and water for reduce and solve potential environmental risks posed by VAs.

\section{ACKNOWLEDGEMENTS}

This work was carried out with the support of "Cooperative Research Program for Agriculture Science \&Technology Development (Project No. PJ00930201)" Rural Development Administration, Republic of Korea.

\section{REFERENCES}

Asuquo, A. E. and L. J. Piddock 1993 Accumulation and killing kinetics of fifteen quinolones for Escherichia coli, Staphylococcus aureus and Pseudomonas aeruginosa. J. Antimicrob. Chemother., 31: 865-880

Bewick, M. W. M. 1979 The adsorption and release of tylosin by clays and soils. Plant Soil, 51: 363-372

Clayton, L. T. 1993 Taber's Cyclopedic Medical Dictionary 17th ed., Escribano, E., Calpena, A. C., Garrigues, T. M., Freixas, J., Domenech, J., and Moreno, J. 1997 Structure-absorption relationships of a series of 6-fluoroquinolnes. Antimicrob. Agents Chemother., 41: 1996-2000

FDA 2013 Annual report on antimicrobials sold or distributed for food-producing animals in 2011. U.S FDA

Figueroa, R. A., A. Leonard and A. A. Mackay 2004 Modeling tetracycline antibiotic sorption to clays. Environ. Sci. Technol., 38: $476-483$

Gensmantel, N. P., P. Proctor and M. I. Page 1980 Metal-ion catalyzed-hydrolysis of some beta-lactam antibiotics. J. Chem. Soc. Perkin Trans., 2: 1725-1732

Grafe, U. 1992 Biochemie der Antibiotika: Struktur-BiosyntheseWirkmechanismus. Spektrum Akademischer Verlag, Heidelberg, p. 389

Gruber, V. F., B. A. Halley, S. C. Hwang and C. C. Ku 1990 Mobility of avermectin $\mathrm{B}_{1 \mathrm{a}}$ in soil. J. Agric. Food Chem., 38: 886-890

Halling-Sorensen, B., S. Nors Nielsen, P. F. Lanzky, F. Ingerslev, H. C. Holten Lutzhoft and S. E. Jorgensen 1998 Occurrence, fate and effects of pharmaceutical substances in the environment -a review. Chemosphere, 36: 357-393

Halling-Sorensen, B., G. Sengelov, F. Ingerslev and L. B. Jensen 2002 Reduced antimicrobial potencies of oxytetracycline, tylosin, sulfadiazin, streptomycin, ciprofloxacin, and aquindox due to environmental processes. Arch. Environ. Contam. Toxicol., 44: 7-16

Hillel, D. 1980 Fundamental of Soil Physics. Academic Press Inc., New York, p. 413

Juhel-Gaugain, M., J. D. McEvoy and L. A. van Ginkel 2000 Measurements for certification of chlortetracycline reference materials within the European Union: Standards, measure- ments and testing programme. Fres. J. Anal. Chem., $\mathbf{3 6 8}$ 656-663

Kanfer, I., M. F. Skinner and R. B. Walker 1998 Analysis of macrolide antibiotics. J. Chromatogr. A. 812: 255-286

Larson, R. A. and E. J. Weber 1994 Reaction mechanisms in environmental organic chemistry. Boca Raton: Lewis Publishers, p. 433

Mabey, W. and T. Mill 1978 Critical review of hydrolysis of organic compounds in water under environmental conditions. J. Phys. Chem. Ref. Data, 7: 383-415

MAFRA 2013 Act on Criteria and Standards of harmful feed. Notification of MAFRA, p. 2013-2076

Mitchell, S. M., J. L. Ullman, A. L. Teel and R. J. Watts 2014 pH and temperature effects on the hydrolysis of three $\beta$-lactam antibiotics: Ampicillin, cefalotin and cefoxitin. Sci. Total Environ., 466-467: 547-555

National Institutes of Health (NIH) 1999 U.S. National Library of Medicine. Toxnet - Toxicolgy Data Network. [Online], Available: http://toxnet.nlm.nih.gov/ [7 May 2014]

Kemper, N. 2008 Veterinary antibiotics in the aquatic and terrestrial environment, Ecol. Indic., 8: $1-13$

Nowara, A., J. Burhenne and M. Spiteller 1997 Binding of fluoroquinolne carboxylic acid derivatives to clay minerals. J. Agric. Food Chem., 45: 1459-1463

Osol, A. 1980 Remington's Pharmaceutical Sciences. Mack Publishing Co., Easton, PA, p. 1928

Pathak, S. H. C. 2010 Antibiotics in manure and soil-A grave threat to human and animal health National Academy of Agricultural Sciences, [Online], Available: http://naasindia.org/ Policy\%20Papers/policy\%2043.pdf [7 May 2014]

Pedersen, J., M. Yeager and I. Suffet 2003 Xenobiotic organic compounds in runoff from fields irrigated with treated wastewater. J. Agric. Food Chem., 51: 1360-1372

Pinck, L. A., W. F. Holton and F. E. Allison 1961a Antibiotics in soils: 1. Physico-chemical studies of antibiotic-clay complexes. Soil Sci., 91: 22-28

Pinck, L. A., D. A. Soulides and F. E. Allison 1961b Antibiotics in soils: II. Extent and mechanisms of release. Soil Sci., 91: 94-99

Pusino, A., S. Petretto and C. Gessa 1996 Montmorillonite surface-catalyzed hydrolysis of fenoxaprop-ethyl. J. Agric. Food Chem., 44(4): 1150-1155

Rabolle, M. and N. H. Spliid 2000 Sorption and mobility of metronidazole, aquindox, oxytetracycline and tylosin in soil Chemosphere, $\mathbf{4 0}(7)$ : 715-722

Regassa, T. H., R. K. Koeklsch, R. F. Randle and A. A. Abunyawa 2009 Antibiotic use in animal production-Environmental concern. Univ. Nebraska-Linciln Extension RP196 [Online], Available: http://www.ianrpubs.unl.edu/live/rp196/build/rp196. pdf [7 May 2014]

Renee, J. 2011 Potential trade implications of restrictions on antimicrobial use in animal production. Congressional Research Service CRS. Report for congress prepared for members and committees of congress. Congressional Research Service, USA. p. 118

Salvatore, M. J. and S. E. Katz 1993 Solubility of antibiotics used in animal feeds in selected solvents. J. Assoc. Off. Anal. Chem. Int., $\mathbf{7 6}(5)$ : 952-956

Sarmah, A. K., M. T. Meyer and A. B. A. Boxall 2006 A global perspective on the use, sales, exposure pathways, occurrence, fate and effects of veterinary antibiotics in the environment. Chemosphere, $\mathbf{6 5}(5)$ : 725-759

Sassman, S. A. and L. S. Lee 2005 Sorption of three tetracyclines by several soils: assessing the role of $\mathrm{pH}$ and cation exchange. Environ. Sci. Technol., 39(19): 7452-7459

Singh, A. P. and S. Mishra 2013 Studies on Antibiotic Production by Soil Microflora and their Biochemical Characterization form Different Industrial Waste Polluted Soil Samples in Uttar Pradesh \&Uttarakhand. India. Int. J. Pharm. Bio. Sc., 7(4): $32-43$

Sithole, B. B. and R. D. Guy 1987 Models for oxytetracycline in aquatic environments. II. Interactions with humic substances. 
Water Air Soil Pollute., 32: 315-321

Suan, D. T. and L. V. Dmitrenko 1994 Sorption kinetics of the antibiotic oxytetracycline on ion exchange materials. Appl. Environ. Microbiol., 30(6): 634-636

Syracuse Research Corporation (SRC) 2001 Environmental Fate Data Base. [Online], Available: http://www.syrres.com/ esc/efdb.htm. [7 May 2014]

Thiele-Bruhn, S. 2003 Pharmaceutical antibiotic compounds in soils-a review. J. Plant Nutr. Soil Sci., 166(2): 145-167

Thiele-Bruhn, S., T. Seibicke, H. R. Schulten and P. Leinweber 2004 Sorption of Sulfonamide Pharmaceutical Antibiotics on Whole Soils and Particle-Size Fractions. J. Environ. Qual.,
33(4): 1331-1342

Torrents, A., Stone A. T. 1994 Oxide surface-catalyzed hydrolysis of carboxylate esters and phosphorothioate esters. Soil Sci. Soc. Am. J., 58(3) 738-745

Waterman, K. C., R. C. Adami, K. M. Alsante, A. S. Antipas, D. R. Arenson, R. Carrier, J. Hong, M. S. Landis, F. Lombardo, J. C. Shah, E. Shalaev, S. W. Smith and H. Wang 2002 Hydrolysis in pharmaceutical formulations. Pharm. Dev. Technol., 7(2) $113-146$

Wilson, R. C. 1981 The macrolides. In: Steel, C.P., Beran, G.W. (Eds.), Antibiotics, Sulfonamides, and Public Health. CRC Press, Boca Raton, FL 